\title{
¿Qué pan de molde compro? Una propuesta didáctica para introducir el debate quimiofóbico en el aula
}

\author{
Lorenzo Hernández Villalobos
}

IES Gádor. Almería. España

[Recibido el 10 de junio de 2019, aceptado el 08 de octubre de 2019]

En este artículo se hace un análisis de la imagen de la química en la sociedad, la prensa y la publicidad, y se argumenta la necesidad de introducir el debate quimiofóbico en el aula de ciencias. Para ello, se propone una secuencia de actividades para el análisis crítico de un anuncio publicitario donde se fomenta una mala imagen de la química.

Palabras clave: publicidad; natural y artificial; quimiofobia; pensamiento crítico.

\section{Which sliced bread should I buy? A didactic proposal to introduce the chemophobic discussion in the classroom}

This article describes an analysis of the view of chemistry in society, written media and advertising, and discussed the need of introducing the chemophobic discussion in science classes. In order to get this, a sequence of activities is proposed for the critical analysis of an advertisement in which a bad view of chemistry is fostered.

Key words: advertising; natural and artificial; chemophobia; critical thinking. 


\section{Introducción}

\section{La imagen de la Química}

En las modernas sociedades desarrolladas la imagen pública de la Química está en crisis (Vázquez y Manasero, 2006). De hecho, la IUPAC definió el término quimofobia como el "miedo irracional a los productos químicos" (Duffus, Nordberg y Templeton, 2007). La quimiofobia surgió en la década de los años 1960 ligada a la creciente preocupación sobre el uso de pesticidas como el DDT. Actualmente, las encuestas y sondeos de opinión pública reflejan y cuantifican claramente las dimensiones de la quimiofobia en Europa (CEFIC, 2004) siendo la tasa más alta de aprobación hacia la Química en Europa en Alemania y España (62\% aprueba), por lo que sigue existiendo aún mucho espacio para la mejora (Vázquez y Manasero, 2006). Esta mala imagen no es nueva ya que un recorrido histórico por la imagen pública de la Química (Chamizo, 2011), en las cinco revoluciones establecidas por Jensen (1998), evidencia que su mala fama la ha perseguido desde sus inicios.

Actualmente, los factores que influyen en su mala imagen pública son variados: controversias del uso de ciertos pesticidas como el $\mathrm{DDT}^{1}$ (años 60); deterioro del medio ambiente; desarrollo de gases de guerra, armas químicas y mejora de explosivos; su relación con las drogas y alucinógenos; desastres en industrias químicas; el desarrollo de alimentos ultraprocesados y transgénicos; o la mala fama a veces injustificada de ciertos aditivos alimentarios. Los medios de comunicación tienen una gran responsabilidad en su imagen y es común encontrarse titulares como "Incautan químicos para elaborar los narcóticos" (El Sol del Centro, 2018) o "La UE retira el 10\% de juguetes con químicos peligrosos del mercado antes de la campaña de Navidad" (Europa Press, 2018).

Dos factores relativamente recientes son el abuso de la quimiofobia en la publicidad (principalmente en la alimentaria) y las controversias relacionadas con estudios científicos que protagonizan titulares de prensa alarmistas como "La sacarina es un agente potencial del cáncer en seres humanos" (El País, 1978), "Coca-Cola y Pepsi cambian la receta para evitar una 'etiqueta de cáncer'” (El Mundo, 2012), “¿Aditivos que producen cáncer?” (La Razón, 2016), "Los emulsionantes que se añaden a los alimentos parecen causar cáncer colorrectal" (ABC, 2016) o "Científicos de Harvard relacionan un aditivo común en el pan de molde con la diabetes y la obesidad" (El País, 2019). Este tipo de titulares confunden al consumidor ya que suelen estar basados en modelos animales donde al administrar dosis muy altas de un determinado aditivo o pesticida a ratones o ratas, generalmente, éstos sufren distintos problemas de salud, tumores cancerígenos entre otros. Sin embargo, los resultados son difícilmente extrapolables a las cantidades que consumen las personas en los alimentos. Otros factores que se añaden a la negativa percepción pública de la Química son la imagen de los químicos que aparece asociada con mayor proporción que la de otros científicos a los rasgos más negativos del estereotipo (Ball, 2004) y los relacionados con la dimensión sociológica externa a la propia ciencia como la influencia socio-política: gobiernos, grupos de presión, lobbies, etc. (García-Carmona, Acevedo-Díaz y Aragón-Méndez, 2018).

1 El DDT se empezó a usar para proteger de la malaria a los soldados que combatían en las islas del Pacífico. A partir de la Segunda Guerra Mundial diezmó las poblaciones de piojos que provocan el tifus, las de las pulgas que ocasionan la peste y las de los mosquitos de la malaria y de la fiebre amarilla. Además, acababa con muchas plagas de cultivos. Respecto a su toxicidad en seres humanos, no se ha demostrado de forma clara que los niveles que alcanzó en el medio ambiente fuesen tóxicos para los seres humanos y se calcula que su utilización salvó decenas de millones de vidas. 
Sin embargo, esta visión de la Química está sesgada ya que no se suele citar todos los logros que dicha ciencia nos ha proporcionado, tanto en la comprensión del mundo que nos rodea y en el aporte a otras ramas del conocimiento, como en la aplicación a la alimentación, textiles, combustibles, transportes, tecnología, comunicaciones, potabilización de aguas, aislantes, fármacos (medicinas contra el cáncer), anestesias, vacunas, higiene y salud, medicina, nuevos materiales, recubrimientos antioxidantes, etc. Sumados a otros factores, la potabilización del agua, las vacunas y los antibióticos salvan millones de vidas al año y explican un aumento de la esperanza de vida destacado. En gran parte, la mejora de los diagnósticos, terapias e higiene, así como el cambio radical en la posibilidad de diagnosticar y tratar y prevenir enfermedades, ha sido gracias a los descubrimientos científicos de la Química y la Física. A modo de ejemplo, en España, según los datos de esperanza de vida a lo largo del siglo XX (Gisbert y Pallejà, 2006), en el año 1900 la esperanza de vida era de 35,7 años para mujeres y 33,85 para los hombres. En 1998, de 82,16 y 75,25 para mujeres y hombres, respectivamente. En 2017 la esperanza de vida es de unos 83 años, según la OCDE. En la Figura 1 se muestra la esperanza de vida media en distintos continentes desde 1771 hasta el 2015. Observando dichos datos cabe preguntarse, tal como hace Mulet (2014, p. 103), "¿dónde está el problema de la industrialización?". No es exagerado afirmar, como apunta Atkins $(2015$, p. 11), que en un mundo sin productos químicos sería como retroceder a los tiempos de la Edad de Piedra.

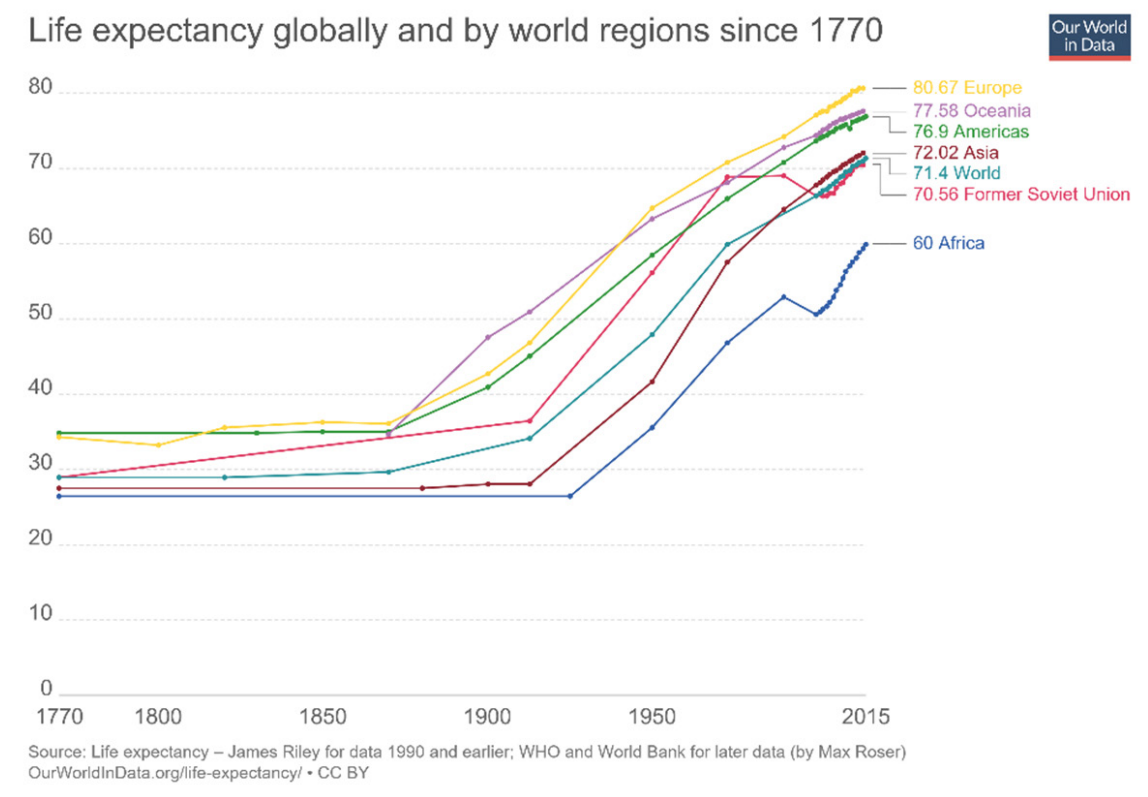

Figura 1. Esperanza de vida en distintos continentes desde el año 1770 al 2015. Fuente: https://ourworldindata.org

Un ejemplo típico e ilustrativo para mostrar estas dos caras del uso de la Química (aplicable a cualquier tipo de conocimiento) es el caso del químico alemán Fritz Haber (18681934). Por un lado, sintetizó el "gas mostaza" (bis(2-cloroetil) sulfonato) que fue la causa de unas 100.000 muertes en la Primera Guerra Mundial. Por otro, fue galardonado con el Premio Nobel de Química de 1918 por su desarrollo de la síntesis del amoniaco. En 1909, Carl Bosh perfeccionó un procedimiento inventado por Fritz Haber que empleaba metano y vapor para extraer el nitrógeno del aire y convertirlo en fertilizante a escala industrial, sustituyendo las enormes cantidades de excrementos de pájaros que se había 
necesitado previamente para devolver el nitrógeno a los suelos empobrecidos ${ }^{2}$. Como señala Pinker (2018, p. 107), esos dos químicos encabezan la lista de los científicos del siglo XX que salvaron el mayor número de vidas en la historia, que ha llegado a estimarse en unos dos mil setecientos millones ${ }^{3}$.

\section{Consecuencias de la quimiofobia}

La publicidad quimiofóbica, más allá de ser inocua, influye en el consumidor de tal modo que el 50,8 \% de los consumidores españoles estaría dispuesto a pagar más por alimentos sin aditivos al considerarlos más sanos, según las conclusiones del informe "LifeStyle 2012" realizado por Worldpanel (López-Nicolás, 2016, p. 148).

Otra consecuencia más grave es que puede llevar a abandonar hábitos saludables, como pasteurizar los alimentos (Figura 2), comer pescado por miedo al mercurio, o trasladar dicha fobia a otros ámbitos como la salud. Así, muchas personas optan por medicinas alternativas, productos o dietas naturales para tratarse enfermedades graves (es llamativo el caso de Steve Jobs que teniendo un cáncer de páncreas operable se trató con acupuntura, dietas vegetarianas o hierbas medicinales, entre otros tratamientos pseudocientíficos) o padres que rechazan vacunar a sus hijos protagonizando titulares como "Muere el niño de 6 años de Olot infectado de difteria" (El Mundo, 2015) o "Alarma por un brote récord de sarampión en Europa"(El País, 2018). Efectivamente, de seguir así, volveremos a la Edad de Piedra.

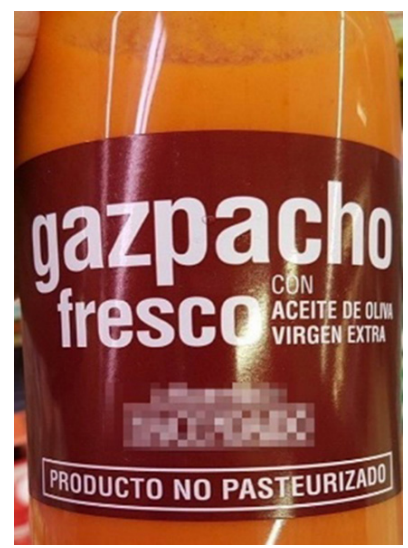

Figura 2. Gazpacho fresco no pasteurizado

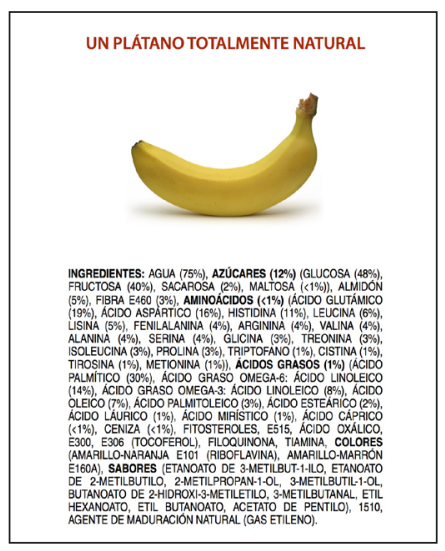

Figura 3. Póster de profesor de química de instituto James Kennedy. Traducido por Mauricio-José Schwarz

Contra esta avalancha de noticias con el mensaje de "todo da cáncer", "contiene químicos" o "nos están envenenando", donde se usa la estrategia del miedo, luchan, con la ayuda de la divulgación científica, plataformas y blogs escritos por científicos y científicas como "Naukas", "Scientia", "Gominolas de petróleo", "El blog del Búho" o "dimetilsulfuro", entre muchos otros, y libros como "Los productos naturales ivaya timo!" (2011), "Comer

2 Hasta el año 1900 el nitrógeno, fundamental tanto para la elaboración de fertilizantes como precursor de explosivos de uso militar, era obtenido principalmente del guano depositado por aves en islas del Pacífico y de la extracción de minas, la más productiva situada al norte de Chile. Las naciones europeas temían y predecían un futuro apocalíptico debido a la escasez de nitrógeno para la producción de alimentos.

3 https://www.scienceheroes.com/ 
sin miedo" (2014) o "Transgénicos sin miedo" (2017), de J.M. Mulet, "Vamos a comprar mentiras" (2016), de J. M. López Nicolás, o “Los falsos mitos de la alimentación" (2018) de M. Herrero Calleja.

Algunas iniciativas curiosas han sido las del profesor de química de instituto James Kennedy que enseña en Melbourne, Australia, que en 2014 concibió la idea de hacer un cartel ${ }^{4}$ con los ingredientes de un plátano "totalmente natural" (Figura 3). Su objetivo era implicar a sus alumnos y demostrarles que la química está a todo nuestro alrededor. Después decidió compartirlo en Internet y fue un éxito instantáneo en redes sociales como Reddit. Este tipo de imágenes son muy ilustrativas para enseñar en el aula.

Aunque se está haciendo un gran esfuerzo, parece difícil combatir a la publicidad y a los medios de comunicación masivos, o a raperos tan influyentes (sobre todo en la población juvenil) como Nach que escriben canciones quimiofóbicas como "anticuerpos". Además, la quimiofobia no está presente solamente en medios informales, sino que también hace acto de presencia en libros de texto (Figura 4). Por esto, desde la enseñanza de las ciencias en sus distintos niveles, tenemos la obligación de transmitir una buena imagen de la Química, fomentando el pensamiento crítico (en adelante PC) para la toma de decisiones responsables.
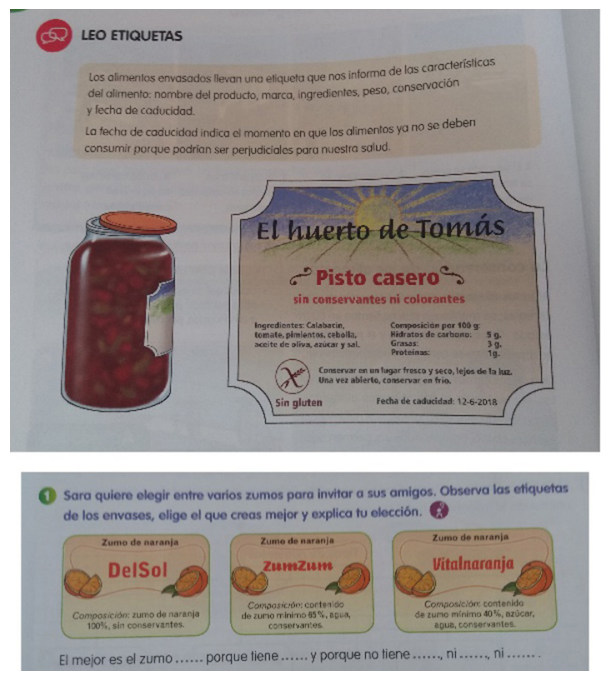

Figura 4. Dos ejemplos de ejercicios quimiofóbicos presentes en un libro de texto de 3 ㅇ de primaria

\section{Objetivos de la investigación}

Este trabajo tiene como principal objetivo introducir el debate quimiofóbico en el aula a través de una secuencia de actividades donde se usa la publicidad y la prensa como recurso. Concretamente se utiliza un anuncio publicitario donde se hace un uso erróneo del concepto "natural". Además, se proponen una serie de actividades y de ejercicios numéricos como argumento para rebatir si dicha quimiofobia está justificada, sobre todo en el contexto alimentario. De este modo, se pretende trabajar algunas dimensiones del PC como el análisis crítico de la información, la argumentación y la toma de decisiones, educando así al alumnado como consumidor y como ciudadano responsable.

4 https://jameskennedymonash.wordpress.com/2016/01/22/all-natural-banana-poster-series pdfs/ 


\section{Marco teórico}

Aunque la finalidad de este artículo no es realizar un análisis exhaustivo de las distintas definiciones de PC, resulta oportuno comentar algunos aspectos de este, así como su relación con el análisis de anuncios publicitarios.

Según el R.D 1105/2014, el PC constituye un aspecto importante de las competencias básicas en ciencia y tecnología, en la medida en que éstas "capacitan a ciudadanos responsables y respetuosos que desarrollan juicios críticos sobre los hechos científicos y tecnológicos" (Blanco, España y Franco-Mariscal, 2017).

EI PC ha sido definido por multitud de autores desde distintas perspectivas. Así por ejemplo la filosofía manifiesta que la principal característica del PC es la duda, la sospecha, el escepticismo, aplicado a todo y, en particular, a los discursos y/o acciones que reproducen y legitiman lo ya establecido (Habermas, 1992; Marcuse 1994; citado en Solbes y Torres, 2013). Desde un enfoque psicológico, se relaciona con el "pensamiento razonable reflexivo buscando decidir qué creer o qué hacer" (Ennis, 1996), con la resolución de problemas, la argumentación, evitar falacias de argumentación (respecto a la probabilidad, o la causalidad/correlación, etc.) (Halpern, 1998) o con el razonamiento argumentado apoyado por pruebas, concediendo una gran importancia a preparar al alumnado para la vida (Kuhn, 1992). En didáctica de las ciencias, el PC se relaciona con la capacidad de hacer elecciones racionales y juicios fundamentados como elementos de las decisiones que se emplean para resolver problemas (Yager, 1993); con el "modo de pensar -sobre cualquier tema, contenido o problema- en el cual el pensante mejora la calidad de su pensamiento al apoderarse de las estructuras inherentes del acto de pensar y al someterlas a estándares intelectuales" (Paul y Elder, 2006); con no creer todo lo que se oiga y pedir pruebas de los enunciados (Smolin, 2007); con las capacidades de cuestionar la validez de los argumentos, rechazar conclusiones no basadas en razones válidas, detectar tendencias o errores de pensamiento y evaluar la credibilidad de las fuentes de información (Vieira, Tenreiro Vieira y Martins, 2010; citado en Solbes 2012); o con la capacidad de desarrollar una opinión independiente, adquiriendo la facultad de reflexionar sobre la sociedad y participar en ella (Jiménez Aleixandre, 2010). En algunos textos de divulgación científica podemos encontrar otras definiciones de PC:

"Consiste en cuestionar sistemáticamente las premisas sobre las que se apoya nuestro tejido de creencias, muchas veces implícitas y difíciles de reconocer, evitar los sesgos emocionales y cognitivos, analizar la validez de la información obtenida y de los razonamientos empleados, y contrastarlos en lo posible con la prueba empírica." (Altschuler, 2017, p. 26).

El uso de la publicidad en el aula para fomentar el PC está justificado por varios motivos: es uno de los fenómenos característicos de nuestro tiempo y es uno de los elementos que sirve para moldear la opinión de los ciudadanos y para crear hábitos de comportamiento (Campanario, Moya y Otero, 2001); constituye, sin duda, uno de los contextos sociales de interés para el alumnado (Blanco, España y Rodríguez, 2012) y de gran influencia en la vida de los adolescentes; en el ámbito específico de la alimentación, la influencia de la publicidad en la vida de los adolescentes está bastante estudiada sociológicamente (Girón, Blanco y Lupión, 2015) y supone uno de los canales por los que, de forma más o menos implícita, llega la ciencia a los ciudadanos (Blanco, 2004). Por todo esto, se ha planteado la necesidad de su tratamiento educativo (Arconada, 2006) y su utilización en la enseñanza de las ciencias (Pro y Rodríguez, 2010).

En la enseñanza de las ciencias, la publicidad ha sido un recurso recurrente con diversas finalidades: para analizar las concepciones de los alumnos (Jiménez-Liso, de Manuel, González y Salinas, 2000); como estrategia para fomentar el PC analizando un anuncio 
publicitario de un conocido alimento probiótico (Girón et al., 2015; Blanco et al., 2017) o para analizar y gestionar información reflexionando acerca del significado de la palabra "natural" (Ezquerra, Fernández-Sánchez y Magaña, 2015).

En este artículo, para plantear la controversia socio-científica "natural vs artificial" en el aula se recurre a una estructura estandarizada propuesta para las dinámicas lingüísticas (Lawrence, White y Snow 2010, 2011) compuesta por cuatro etapas: presentación del dilema, lectura, debate y escritura de un ensayo. Sin embargo, en esta secuencia se introduce también la visualización de vídeos publicitarios y la necesidad de realizar cálculos numéricos a la hora de argumentar una respuesta.

\section{La publicidad: a favor de la ciencia, en contra de la química.}

“Máxima: El curare y el virus del Ébola son naturales." D.R. Altschuler

Según la última encuesta de Percepción Social de Ciencia y Tecnología realizada por la Fundación Española de Ciencia y Tecnología (FECYT) los grupos profesionales más reconocidos, una vez más, son los Médicos/as $(4,67)$ y Científicos/as $(4,53)$ (FECYT, 2018). Paradójicamente, los publicistas aprovechan la confianza que la sociedad muestra en la labor de los científicos para vender productos aludiendo a la autoridad de la ciencia ("científicamente probado"), o a los supuestos avances en la industria de la alimentación (alimentos funcionales que ayudan a las defensas, que disminuyen el colesterol, etc.), el llamado "marketing pseudocientífico" (López-Nicolás, 2014), mientras que siguen transmitiendo una mala imagen de la Química ("100\% natural", "sin aditivos", "sin químicos"), como si la Química no fuera una ciencia ni tuviera nada que ver con la cantidad, la seguridad y la calidad de los alimentos. Por tanto, la publicidad cae en la contradicción de usar en unas ocasiones lo artificial (alimentos funcionales) como beneficioso y en otras como perjudicial (sin aditivos). Por ejemplo, en el envase de leche (Figura 5) se puede leer al mismo tiempo "Calcio natural 100\%" y "Enriquecido en Calcio" (es decir, que se ha añadido de manera artificial): "Leche $100 \%$ natural. Enriquecida en calcio, fósforo, vitamina A, D y E y ácido fólico".

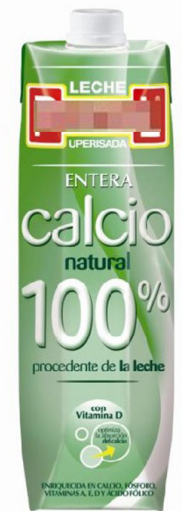

Figura 5. Envase de leche calcio $100 \%$ natural

El mensaje publicitario y en concreto el quimiofóbico suele usar distintos tipos de falacias, siendo la más frecuente la falacia naturalista que se origina en la ambigüedad de la palabra "natural", donde se confunde natural (y orgánico) con bueno. Este argumento es fácil de rebatir ya que no resulta complicado nombrar sustancias naturales que son nocivas e incluso mortales, y artificiales que son beneficiosas: el virus del Ébola y el agua del mar (si la ingerimos habitualmente) son naturales $y$, sin embargo, son perjudiciales para nuestra 
salud; los antibióticos, las vacunas o los fármacos son artificiales y son beneficiosos (si se hace un uso adecuado).

\section{Otras cuestiones para tener en cuenta}

\section{¿Cuándo y cómo introducir el debate quimiofóbico en el aula de secundaria?}

El debate quimiofóbico se puede introducir a principio del curso ( $2 \circ$ o $3 \circ \mathrm{ESO}$ ), para que sea un tema a tratar transversalmente en distintas unidades didácticas, o como introducción en las unidades didáctica sobre alimentación o en "La clasificación de la materia" por varios motivos: porque en primaria, natural/artificial es un criterio básico de clasificación de la materia inerte (Martín del Pozo y Galán, 2012); las conceptos natural y artificial están relacionados con contenidos conceptuales de la unidad como sustancia pura, mezcla, métodos de separación, etc.; y porque el significado popular que se le asigna al término puro, que se utiliza en la vida cotidiana con un significado diferente al de la pureza en química (Caamaño, 2015), contiene una connotación beneficiosa, al igual que natural: respirar aire puro, pura leche de vaca, puro zumo de frutas, $0 \%$ impurezas (Figura 6)... Así, las ideas y estrategias debatidas en el debate quimiofóbico pueden ser aplicadas a la hora de introducir estos conceptos.

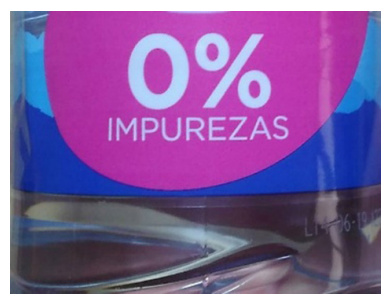

Figura 6. Etiqueta de agua embotellada

\section{¿A qué nos referimos cuando hablamos de natural y artificial?}

Si se quiere debatir sobre los términos natural y artificial, resulta necesario llegar a un consenso sobre sus significados. Si nos referimos a que algo es natural si existe en la naturaleza sin ningún tipo de manipulación humana, la luz del sol, el agua del mar, la miel o las setas, por ejemplo, serían naturales. Contrario a este significado de natural es artificial, que será todo aquello donde sí haya habido cierta elaboración humana, digamos que no existía en la naturaleza antes de la llegada del ser humano. Por ejemplo, una barra de pan o el plástico. Respecto a las sustancias químicas, se pueden dividir en naturales, artificiales y sintéticas. Según Valls y Segura (2015) si una sustancia ha sido elaborada por el ser humano se denomina sintética, dejando el nombre de sustancia natural para los casos en el que el factor humano no haya intervenido en su fabricación. Las sustancias sintéticas pueden ser sintéticas naturales, si ya existen en la naturaleza, o sintéticas artificiales si no están presentes en ella.

Los medios de comunicación no suelen referirse a los significados anteriores, sino que usan el término natural para referirse a productos que, aunque han tenido cierta manipulación humana, son fabricados con ingredientes naturales, es decir, con ingredientes recolectados directamente de la naturaleza: el trigo, la naranja, etc. Así pues, la barra de pan, que con la definición anterior sería artificial, en este caso sería natural. Lo natural se suele asociar a saludable. Los medios se refieren a artificial a todo aquello que contenga sustancias sintéticas, es decir, que se han obtenido en el laboratorio. A esto se refieren cuando se afirma "esto contiene químicos". Se suele asociar a perjudicial. 
Todas las sustancias presentes en el universo, ya sean naturales o artificiales, son de naturaleza química, ya sean en forma de elementos (que se ordenan según la tabla periódica) o como compuestos químicos, que son el resultado de la unión de dos o más elementos. Por tanto, resulta una redundancia decir "sustancia química", todas lo son, y afirmar que algo contiene "químicos" es una frase hecha sin sentido, todo contiene "químicos".

Otro punto de vista es considerar al ser humano un ser vivo producto de la evolución biológica, que forma parte de la naturaleza. Por tanto, es un ser natural con unas ciertas características como la racionalidad y la capacidad de modificar la naturaleza. Desde este punto de vista, toda sustancia sintética sería natural ya que es el producto de la modificación realizada por un ser natural. De este modo, no existiría ninguna diferencia sustancial entre la tela de araña o la miel y el nailon o el plástico.

La ambigüedad de estos términos se puede usar para ir haciendo dudar al alumnado e ir analizando los distintos conceptos que aparecen en la publicidad.

\section{Secuencia de actividades}

A continuación (Tabla 1), se muestra una secuencia de actividades divididas en dos bloques. El primero (actividades de la A1 hasta la A7, mostradas en la tabla 1 ) recurre a las contradicciones presentes en la publicidad, concretamente en un anuncio de pan de molde, para introducir el debate quimiofóbico. El segundo bloque (Tabla 2) está formado por las actividades A8, A9 y A10, donde se realizan cálculos para el análisis de ciertas noticias de prensa con un claro mensaje alarmista y quimiofóbico y se propone la escritura de un ensayo.

Tabla 1. Bloque I. Secuencia de actividades para introducir el debate quimiofóbico

\begin{tabular}{|c|c|c|c|}
\hline Etapa & \multicolumn{2}{|l|}{ Actividades } & Comentarios \\
\hline 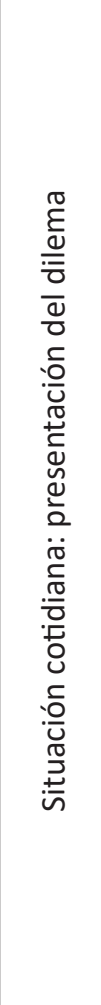 & 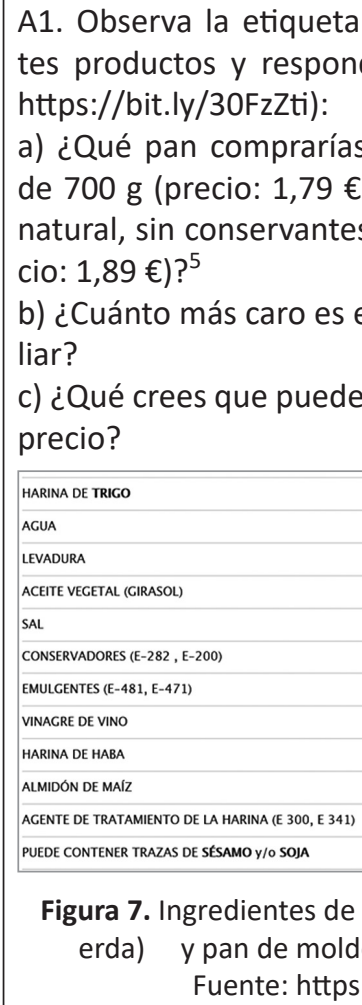 & 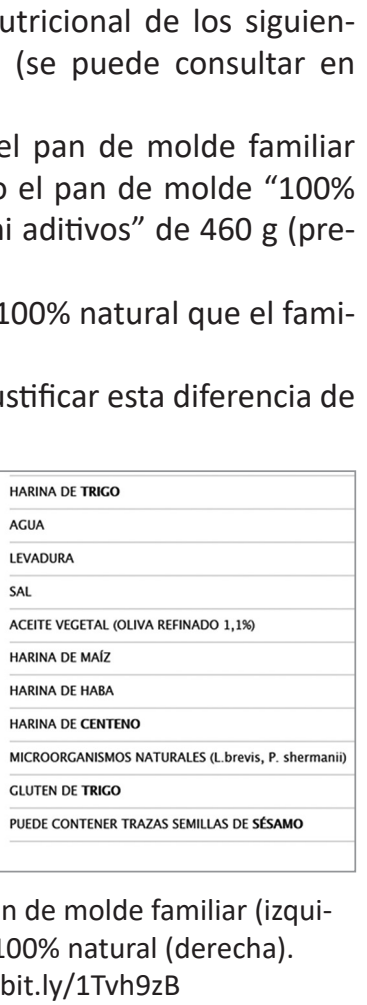 & $\begin{array}{l}\text { En el apartado a) se plantea el } \\
\text { dilema de elegir un alimento más } \\
\text { caro, pero "100\% natural sin con- } \\
\text { servantes ni aditivos", supuesta- } \\
\text { mente más sano, frente a otro más } \\
\text { barato, pero con aditivos. Con la } \\
\text { diferencia de precio se traslada la } \\
\text { idea al consumidor de que el } 100 \% \\
\text { natural debe ser de mayor calidad, } \\
\text { mejor para la salud. } \\
\text { En el b) se trata de calcular real- } \\
\text { mente cuánto más caro es uno } \\
\text { que otro. La primera intuición es } \\
\text { responder que la diferencia es } \\
\text { de } 10 \text { céntimos (un } 5,5 \% \text { ) pero es } \\
\text { necesario calcular el precio por } \\
\text { kilogramo. En el caso del familiar } \\
\text { es de } 2,6 € / \text { kg y en el } 100 \% \text { natural } \\
\text { de } 4,1 € / \text { kg. Por tanto, el natural es } \\
\text { un } 58 \% \text { más caro. }\end{array}$ \\
\hline
\end{tabular}

5 Los precios y las masas de los productos son reales. 
Tabla 1. Bloque I. Secuencia de actividades para introducir el debate quimiofóbico. Continuación

\begin{tabular}{|c|c|c|}
\hline Etapa & ctividades & Comentarios \\
\hline $\begin{array}{l}\frac{0}{0} \\
\frac{0}{0} \\
\frac{0}{0} \\
0 \\
>0 \\
0 \\
\frac{0}{0}\end{array}$ & 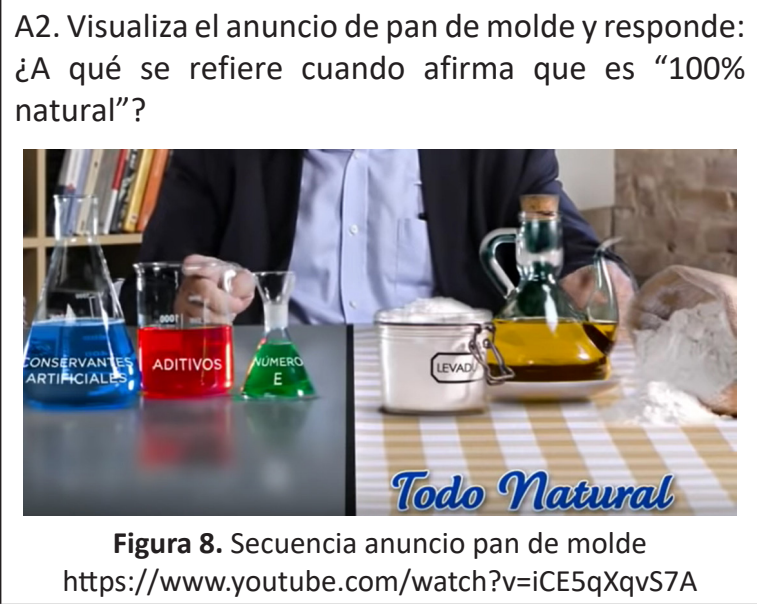 & $\begin{array}{l}\text { Tras esta pregunta pueden surgir } \\
\text { en el aula dos opiniones. Si no es } \\
\text { así, el docente puede proponer } \\
\text { estas dos alternativas: } \\
\text { 1) Natural es aquello que no es } \\
\text { manipulado por el ser humano. Es } \\
\text { decir, el alimento se consume tal y } \\
\text { como está en la naturaleza. } \\
\text { 2) Natural es aquello que, aunque } \\
\text { conlleve cierta manipulación, está } \\
\text { fabricado con sustancias naturales, } \\
\text { con materia prima que no ha sido } \\
\text { procesada, que no lleva "químicos". }\end{array}$ \\
\hline 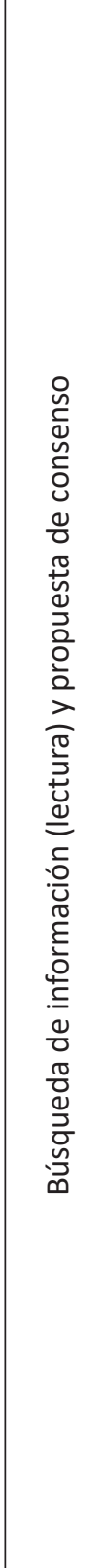 & 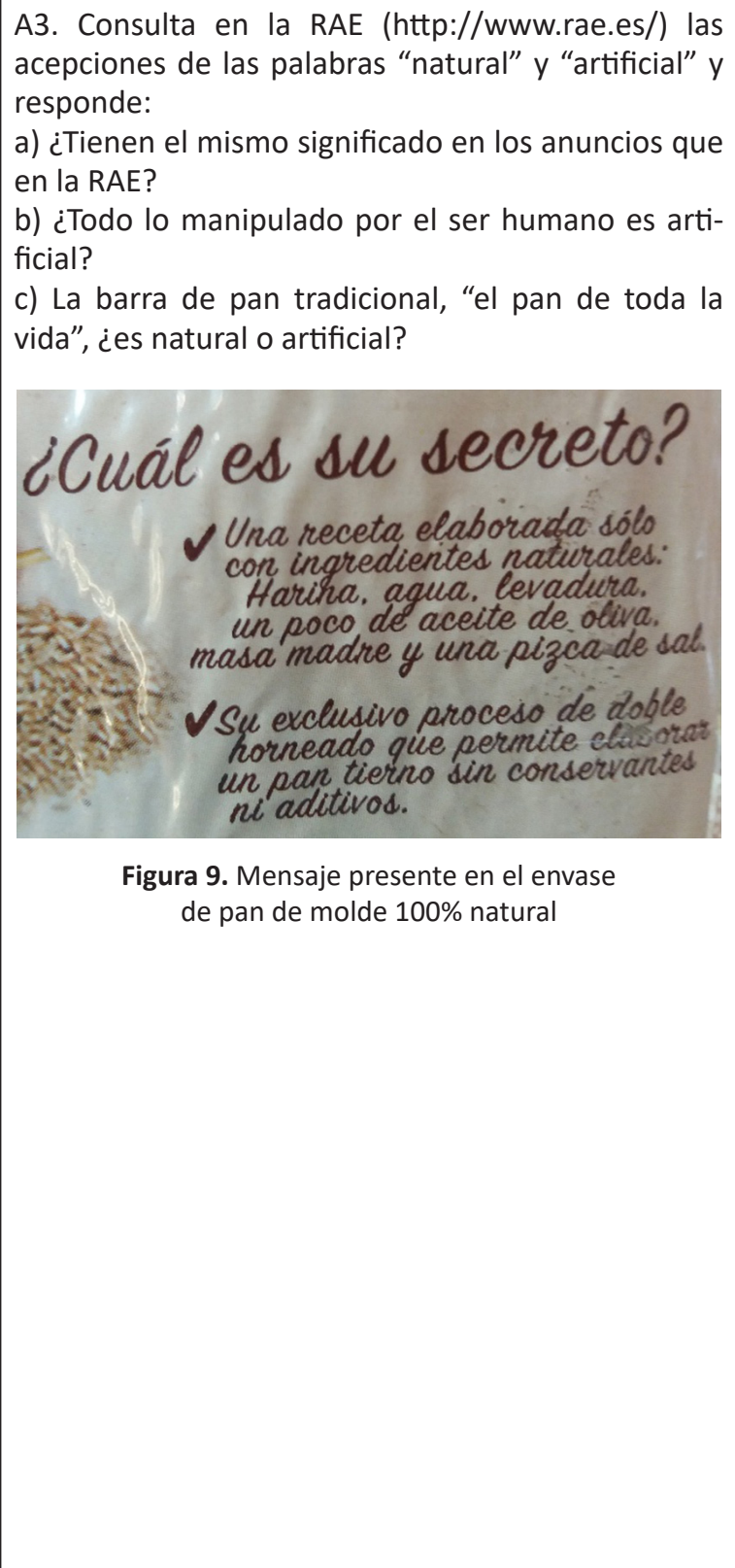 & $\begin{array}{l}\text { El significado en el anuncio no coin- } \\
\text { cide con ninguna definición dada } \\
\text { por la RAE, ya que el significado na- } \\
\text { tural en la publicidad no se refiere a } \\
\text { que ese alimento "crezca en los ár- } \\
\text { boles" o se recolecte en el bosque, } \\
\text { sino que ha sido elaborado con } \\
\text { productos naturales, es decir, que } \\
\text { dichos productos no han sido ma- } \\
\text { nipulados o procesados. Incluso se } \\
\text { indica explícitamente en el paquete } \\
\text { (Figura 9): "Una receta elaborada } \\
\text { sólo con ingredientes naturales". } \\
\text { Respecto a la cuestión b) y c) el } \\
\text { alumnado puede contestar que no } \\
\text { todo lo manipulado por el ser hu- } \\
\text { mano es artificial si está hecho de } \\
\text { sustancias naturales, no manipula- } \\
\text { das ni procesadas. En caso de duda } \\
\text { se puede usar este ejemplo: si una } \\
\text { naranja se exprime con un exprimi- } \\
\text { dor (máquina inventada por el ser } \\
\text { humano, es decir, artificial) ¿ese } \\
\text { zumo es natural o artificial? ¿Hay } \\
\text { alguna diferencia si se exprime con } \\
\text { una máquina o se exprime con las } \\
\text { manos? Ante estas cuestiones, el } \\
\text { alumnado no suele dudar que el } \\
\text { zumo es natural ya sea exprimido } \\
\text { con una máquina o con la mano. } \\
\text { Con este tipo de reflexiones se pue- } \\
\text { de alcanzar un consenso respec- } \\
\text { to al significado natural que se usa } \\
\text { en publicidad: no se refiere a que } \\
\text { no hay elaboración humana, sino a } \\
\text { que la materia prima no ha sufrido } \\
\text { ningún tipo de manipulación o pro- } \\
\text { cesado. Una vez llegado al consen- } \\
\text { so se puede seguir debatiendo para } \\
\text { poner a prueba dicha definición. }\end{array}$ \\
\hline
\end{tabular}


Tabla 1. Bloque I. Secuencia de actividades para introducir el debate quimiofóbico. Continuación

\begin{tabular}{|c|c|c|}
\hline Etapa & Actividades & Comentarios \\
\hline $\begin{array}{l}\stackrel{0}{\pi} \\
\stackrel{0}{0} \\
0 \\
0\end{array}$ & $\begin{array}{l}\text { A4. En el anuncio visualizado en la } \mathrm{A} 2 \text {, ¿̇con qué se } \\
\text { asocia el término "natural" y "artificial", con algo } \\
\text { beneficioso o perjudicial? }\end{array}$ & $\begin{array}{l}\text { Es evidente que en el anuncio } \\
\text { se usa el término natural como } \\
\text { beneficioso, y artificial como per- } \\
\text { judicial, tóxico (Figura 8). Se rela- } \\
\text { ciona lo natural con utensilios y } \\
\text { alimentos cotidianos (levadura, } \\
\text { aceite, etc.), mientras que lo arti- } \\
\text { ficial con conservantes, aditivos, } \\
\text { números E y con material típico de } \\
\text { un laboratorio de química (vaso de } \\
\text { precipitado o matraz Erlenmeyer). } \\
\text { Además, estas sustancias se pre- } \\
\text { sentan con colores muy llama- } \\
\text { tivos dando la sensación de ser } \\
\text { venenosos. Una vez llegado a otro } \\
\text { consenso, que se usa el término } \\
\text { natural como beneficioso y artifi- } \\
\text { cial como perjudicial, se plantea la } \\
\text { siguiente actividad. }\end{array}$ \\
\hline $\begin{array}{l}\stackrel{0}{\pi} \\
\stackrel{0}{0} \\
0 \\
0\end{array}$ & $\begin{array}{l}\text { A5. Indica si consideras que las siguientes sustancias } \\
\text { son naturales o artificiales y beneficiosas o perjudi- } \\
\text { ciales (si son ingeridas) para la salud: antibióticos, } \\
\text { agua del mar, tabaco, aditivo E300, virus del Ébola, } \\
\text { ácido cítrico, vitamina C, aditivo E330, setas veneno- } \\
\text { sas, sal común, leche materna, leche de vaca, setas } \\
\text { comestibles y vacunas. }\end{array}$ & $\begin{array}{l}\text { Con esta actividad se pretende } \\
\text { que el alumnado sea consciente } \\
\text { de que no hay relación entre que } \\
\text { una sustancia sea natural o arti- } \\
\text { ficial con que sea beneficiosa o } \\
\text { perjudicial. Por ejemplo, existen } \\
\text { sustancias naturales, como el agua } \\
\text { de mar, las setas venenosas, el } \\
\text { virus del Ébola o el tabaco, que no } \\
\text { son beneficiosas; sustancias natu- } \\
\text { rales que son beneficiosas, como } \\
\text { el ácido cítrico, la vitamina C, la } \\
\text { sal común (siempre que se con- } \\
\text { suma con moderación) o la leche } \\
\text { materna; y sustancias artificiales } \\
\text { que son beneficiosas (si su uso es } \\
\text { correcto) como los antibióticos y } \\
\text { las vacunas. En algunas sustancias } \\
\text { se podría responder NS/NC o que } \\
\text { depende de la dosis. Por ejemplo: } \\
\text { ¿la leche de vaca es segura si se } \\
\text { consume directamente de la vaca? } \\
\text { ¿Qué son el aditivo E300 y E330? } \\
\text { ¿Son artificiales o naturales? ¿Son } \\
\text { beneficiosos o perjudiciales? El } \\
\text { aditivo E300 y E330 corresponden } \\
\text { al ácido ascórbico (vitamina C) y } \\
\text { al ácido cítrico, respectivamente. } \\
\text { Ambos son conservantes natura- } \\
\text { les. En este momento se puede } \\
\text { comentar que existen conservan- } \\
\text { tes naturales que se usan como } \\
\text { aditivos en los alimentos. }\end{array}$ \\
\hline
\end{tabular}


Tabla 1. Bloque I. Secuencia de actividades para introducir el debate quimiofóbico. Continuación

\begin{tabular}{|c|c|c|}
\hline Etapa & Actividades & Comentarios \\
\hline $\begin{array}{l}\stackrel{0}{0} \\
\stackrel{0}{0} \\
0\end{array}$ & $\begin{array}{l}\text { A6. Visualiza el siguiente anuncio de pan de molde } \\
100 \% \text { sin conservantes ni aditivos: } \\
\text { https://www.youtube.com/watch?v=dw1lofuf75s } \\
\text { a) ¿Por qué crees que indica "sin conservantes y sin } \\
\text { colorantes"? ¿Qué sentido se le asigna, positivo o } \\
\text { negativo? } \\
\text { b) ¿Qué función cumplen los microorganismos que } \\
\text { sustituyen a los conservantes? }\end{array}$ & $\begin{array}{l}\text { Con esta actividad se pretende } \\
\text { analizar el sentido de la palabra } \\
\text { "conservante" en la publicidad. Al } \\
\text { indicar que un alimento no con- } \\
\text { tiene conservantes se trasmite el } \\
\text { mensaje de que son perjudiciales } \\
\text { para la salud. No tendría sentido } \\
\text { un mensaje del tipo "sin vitaminas } \\
\text { E y C", resaltando la ausencia de } \\
\text { un componente beneficioso. Sin } \\
\text { embargo, como se ha comentado } \\
\text { en la anterior actividad y como se } \\
\text { comprobará en la siguiente, exis- } \\
\text { ten conservantes naturales como la } \\
\text { vitamina C, el ácido cítrico o la sal, } \\
\text { que forman parte de nuestra dieta } \\
\text { y que no consideramos nocivos. }\end{array}$ \\
\hline 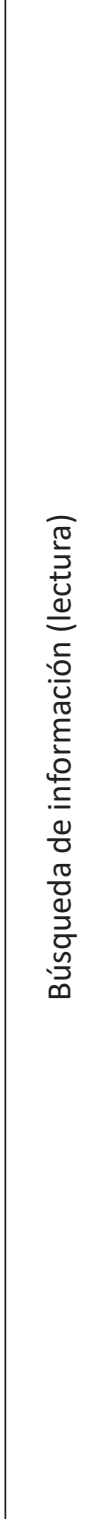 & 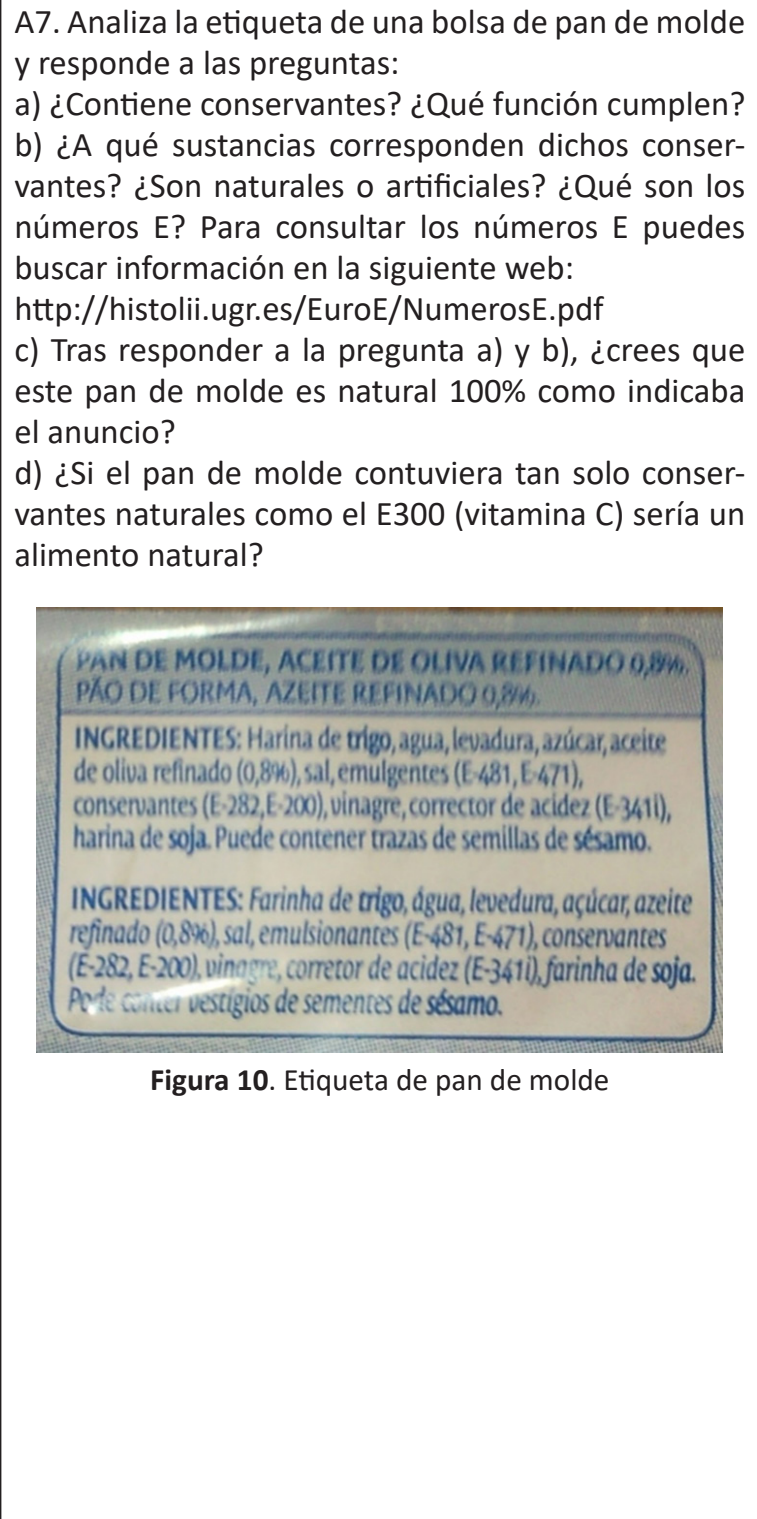 & $\begin{array}{l}\text { Consultada la lista, se puede com- } \\
\text { probar las sustancias que corres- } \\
\text { ponden a los aditivos que contie- } \\
\text { ne el pan de molde y la función que } \\
\text { cumplen: } \\
\text { - Emulgentes: E471, E481, E472e } \\
\text { - Estabilizantes: E481 } \\
\text { - Antioxidantes. E471, E472e y E300 } \\
\text { - Conservadores: E 282, E 200. } \\
\text { - Acidulante: E341 } \\
\text { Casi todos ellos son de origen na- } \\
\text { tural: el E471 (Mono y diglicéridos } \\
\text { de ácidos grasos), el E472e (Ésteres } \\
\text { mono y diacetil tartárico de los } \\
\text { mono y diglicéridos de los ácidos } \\
\text { grasos), el E200 (Ácido sórbico), } \\
\text { E300 (Ácido Ascórbico, vitamina C) } \\
\text { y el E341 (Fosfatos cálcicos). Sólo } \\
\text { dos son de origen artificial: el E481 } \\
\text { y el E282. } \\
\text { En esta actividad debe quedar clara } \\
\text { la función que realizan los conser- } \\
\text { vantes en la alimentación: princi- } \\
\text { palmente preservar las cualidades } \\
\text { nutritivas intactas, impidiendo que } \\
\text { se pudran o se estropeen, evitan- } \\
\text { do pérdidas económicas y la trans- } \\
\text { misión de enfermedades al ser hu- } \\
\text { mano. } \\
\text { Del análisis de la etiqueta se dedu- } \\
\text { ce que no es } 100 \% \text { natural ya que } \\
\text { contiene aditivos sintéticos. Sin } \\
\text { embargo, ante la pregunta de si los } \\
\text { aditivos fueran naturales, aún po- } \\
\text { dría haber respuestas de que sí se- } \\
\text { ría natural ya que está compuesto } \\
\text { por sustancias naturales. }\end{array}$ \\
\hline
\end{tabular}




\section{El veneno está en la dosis}

"Todas las sustancias son venenos, no existe ninguna que no lo sea. La dosis diferencia un veneno de un remedio".

Paracelso.

La frase de Paracelso se suele usar para explicar que la toxicidad de un compuesto químico depende de la cantidad en la que se ingiera. En las siguientes actividades (Tabla 2) se intenta responder a la siguiente pregunta: ¿Qué cantidad de una cierta sustancia debo ingerir para que sea mortal o tenga algún perjuicio para la salud? El alumnado suele ignorar que incluso sustancias cotidianas, saludables y tan necesarias como el agua, pueden producir la muerte si se consumen en grandes cantidades. Por ejemplo, seis litros de agua, 48 cucharaditas de sal o alrededor de 19-24 manzanas enteras podrían llegar a ser letales. En la tabla 2 se muestra la secuencia de actividades propuestas para el cálculo de cantidades que pueden ser perjudiciales para la salud.

Tabla 2. Bloque II. Secuencia de actividades para el cálculo de cantidades perjudiciales para la salud

\begin{tabular}{|c|c|c|}
\hline Etapa & Actividades & Comentarios \\
\hline 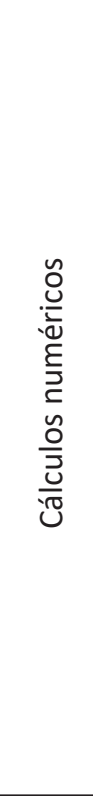 & $\begin{array}{l}\text { A8. La cantidad diaria recomendada de vitamina C } \\
\text { son } 90 \text { mg (hombres adultos) y } 75 \mathrm{mg} \text { (mujeres adul- } \\
\text { tas). Al igual que la deficiencia de vitamina C puede } \\
\text { producir escorbuto, un exceso de esta puede pro- } \\
\text { ducir diarrea, náuseas y cólicos estomacales, entre } \\
\text { otros problemas. El límite máximo diario recomen- } \\
\text { dado para un adulto es de } 2000 \mathrm{mg} \text {. } \\
\text { a) Si una naranja contiene de media } 82 \mathrm{mg} \text {, ¿cuán- } \\
\text { tas naranjas debería ingerir un adulto para llegar al } \\
\text { límite máximo? } \\
\text { b) Si la cantidad de aditivo conservante E300 (vita- } \\
\text { mina C) presente en un pan de molde es de } 130 \\
\text { microgramos (1,3·10-4 g) por rebanada, ¿cuántas } \\
\text { rebanadas habría que consumir para ingerir la can- } \\
\text { tidad diaria recomendada? ¿Y para superar el límite } \\
\text { recomendado para un adulto? }\end{array}$ & $\begin{array}{l}\text { Con cálculos muy sencillos se de- } \\
\text { duce que es absurdo pensar que } \\
\text { se pueda llegar a consumir bas- } \\
\text { tante vitamina C tomando alimen- } \\
\text { tos donde se añade como conser- } \\
\text { vante. El mismo razonamiento se } \\
\text { puede usar si se tratara de un com- } \\
\text { puesto supuestamente tóxico. Es lo } \\
\text { que se plantea en la actividad A9. } \\
\text { Respuesta a) Unas } 24 \text { naranjas al } \\
\text { día. } \\
\text { Respuesta b) Para ingerir la CDR: } \\
\text {-Hombres: } 0,09 \mathrm{~g} / 1,3 \cdot 10^{-4} \mathrm{~g}= \\
692 \text { rebanadas al día. } \\
\text {-Mujeres: } 0,075 \mathrm{~g} / 1,3 \cdot 10^{-4} \mathrm{~g}= \\
577 \text { rebanadas al día. } \\
\text {-Para superar el límite máximo: } \\
2 \mathrm{~g} / 1,3 \cdot 10^{-4} \mathrm{~g}=15385 \text { rebanadas } \\
\text { al día. }\end{array}$ \\
\hline \multirow{5}{*}{ 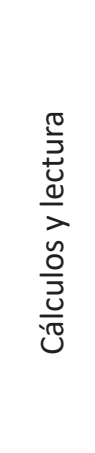 } & A9. Lee la siguiente noticia y responde ${ }^{6}$ : & \\
\hline & $\equiv$ ELPAİS & \\
\hline & 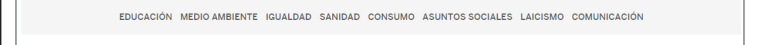 & \\
\hline & $\begin{array}{l}\text { Coca-Cola y Pepsi cambian su composición por un posible } \\
\text { cancerígeno } \\
\text { California ha dictaminado que contitenen un colorante cancerigeno en ratas } \\
\text { La Agencia Europea de seguridad Alimentaratia considera que faltan ensayos }\end{array}$ & \\
\hline & $\begin{array}{l}\text { Figura 11. Noticia de prensa de El País } \\
\text { https://elpais.com/sociedad/2012/03/09/ } \\
\text { actualidad/1331283742_220221.html }\end{array}$ & \\
\hline
\end{tabular}

6 Los cálculos realizados han sido obtenidos del post "Californianos" escrito por Juan José Iruin, Catedrático de Química Física de la UPV/EHU: http://elblogdebuhogris.blogspot.com/2012/03/ californianos.html 
Tabla 2. Bloque II. Secuencia de actividades para el cálculo de cantidades perjudiciales para la salud. Continuación

\begin{tabular}{|c|c|c|}
\hline Etapa & Actividades & Comentarios \\
\hline 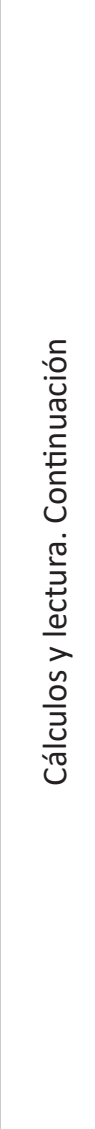 & 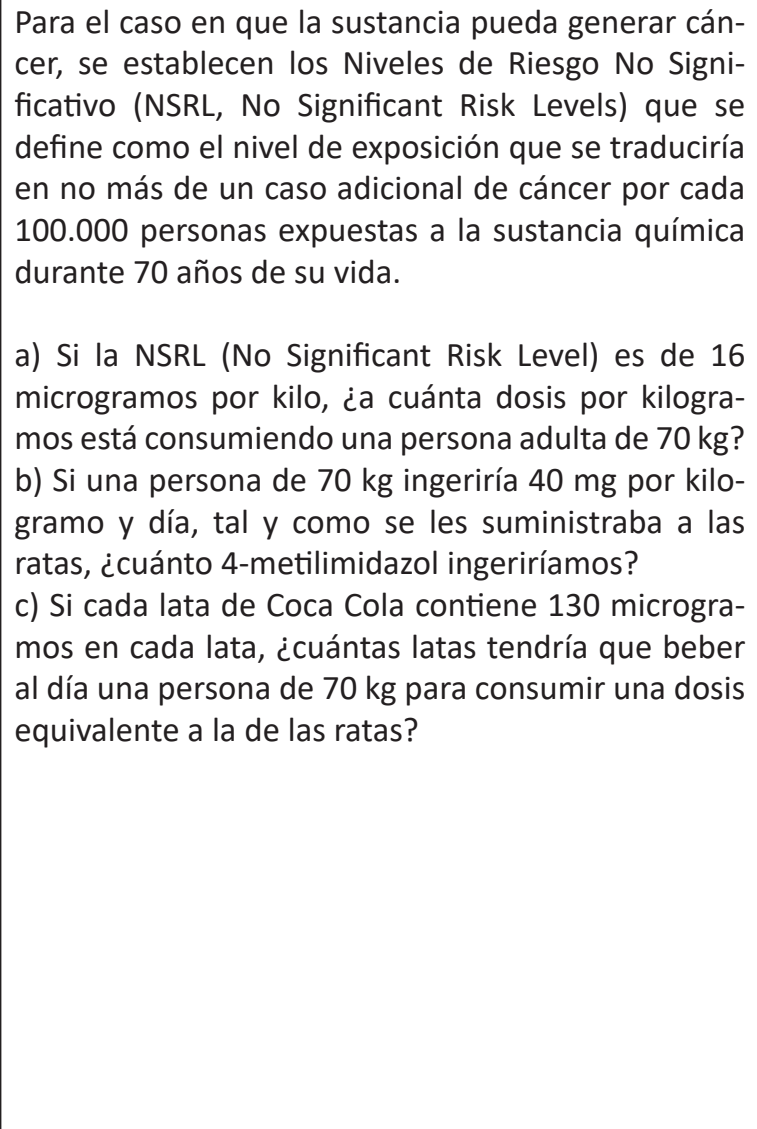 & 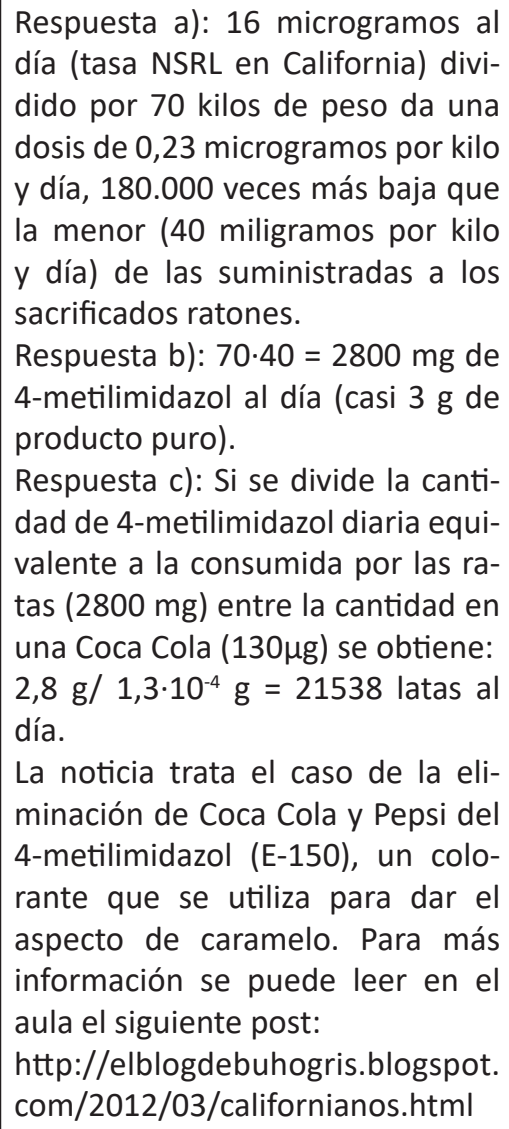 \\
\hline 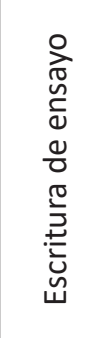 & $\begin{array}{l}\text { A10. Escribe un ensayo breve donde quede reflejada } \\
\text { tu postura sobre el dilema. En él deben aparecer los } \\
\text { ejemplos y datos trabajados en las anteriores acti- } \\
\text { vidades. }\end{array}$ & $\begin{array}{l}\text { Con esta actividad se pretende } \\
\text { que el alumnado pueda poner en } \\
\text { práctica lo aprendido, argumen- } \\
\text { tando de manera razonada su pos- } \\
\text { tura sobre el tema tratado. De este } \\
\text { modo, se trabajan habilidades } \\
\text { como el uso de datos o pruebas, } \\
\text { la justificación y la argumentación. }\end{array}$ \\
\hline
\end{tabular}

\section{Negando la mayor: el trigo y la naranja no son naturales}

Una vez que se ha llegado a este punto, donde se ha construido una determinada definición de "natural", se debe volver al principio y plantear al alumnado si la naranja de donde obtenemos el zumo "natural", el trigo con el que se hace el pan, o el plátano que compramos en el supermercado son naturales. Para ello se le plantean cuestiones como:

- ¿Cómo se alimentaba el ser humano antes del invento de la agricultura?

- ¿Las semillas seleccionadas son naturales o artificiales?

- ¿Existían las frutas y las verduras en la naturaleza tal y como las consumimos hoy día?

- ¿Por qué los plátanos no tienen semillas?

- ¿Cuáles son los orígenes de la mandarina actual? Consultar el árbol genealógico en esta web: https://elpais.com/elpais/2018/02/06/ciencia/1517938851_413612.html 
A modo de ejemplo, se pueden enseñar algunos frutos que estaban presentes en la naturaleza antes de ser modificados por el ser humano y posteriormente (Figura 12):
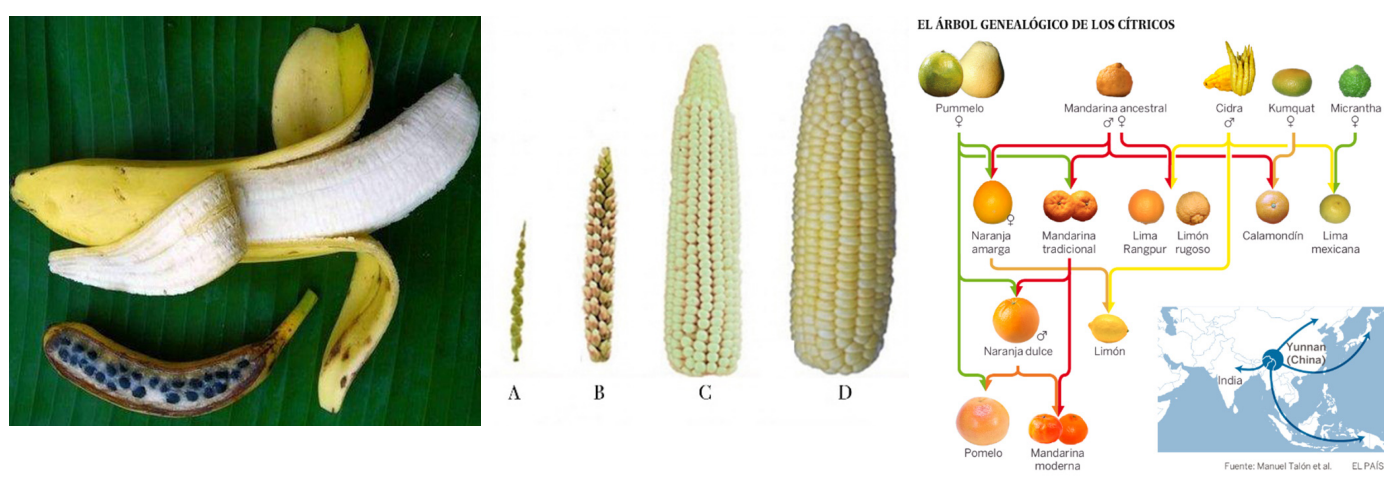

Figura 12. Comparación de alimentos salvajes y manipulados por el ser humano: El plátano y el maíz actual comparados con sus antiguos parientes. Árbol genealógico de los cítricos ${ }^{7}$.

La reflexión se puede extender más planteando al alumnado preguntas del tipo: si el ser humano es natural (producto de la evolución), es una especie más del reino animal, ¿̇no será natural todo lo que produzca? ¿Por qué los túneles cavados por hormigas son naturales y los edificios de los seres humanos son artificiales? ¿El ser humano es el único ser vivo que transforma la naturaleza? ¿La miel y la tela de araña no son transformaciones de la naturaleza que realizan los animales? ¿Acaso los animales no transforman la naturaleza?

\section{Reflexiones finales}

Debido al avance imparable de la quimiofobia se hace necesario trabajar en el aula este tipo de actividades donde el alumnado reflexione sobre la imagen de la Química que transmiten los medios de comunicación, analice críticamente los mansajes publicitarios y concluya que la falacia naturalista es una moda que carece de sentido. Las actividades propuestas pretenden aportar una manera práctica de fomentar el PC pudiendo complementarse con otras temáticas como la problemática ambiental, la ciencia de frontera, la salud (p.ej. azúcares naturales y añadidos), etc. En futuros trabajos se puede analizar los ensayos escritos para evaluar el uso de datos, la argumentación y las conclusiones del alumnado.

\section{Referencias bibliográficas}

Altschuler, D.R. (2017) Contra la simpleza. Ciencia y pseudociencia. Barcelona: Antoni Bosch Editor.

Arconada, M. (2006). Cómo trabajar con la publicidad en el aula. Barcelona: Graó.

Atkins, P.W. (2015). ¿Qué es la química? Madrid: Alianza editorial.

Ball, P. (2004), Chemistry in XXth-century novels, Comunicación presentada en International Conference "The Public Images of Chemistry in the Twentieth Century", Paris, 17-18 septiembre. Recuperado de: http://www.hyle.org/service/chmc2004/abstracts. html\#ball

7 Fuentes: https://www.playgroundmag.net/food/vegetales-ascentrales-podrian-salvarnospellejo_22650668.html; https://elpais.com/elpais/2018/02/06/ciencia/1517938851_413612.html 
Blanco, A. (2004). Relaciones entre la educación científica y la divulgación de la ciencia. Revista Eureka sobre Enseñanza y Divulgación de las Ciencias, 1(2), 70-86. Recuperado de: https://www.redalyc.org/pdf/920/92010202.pdf

Blanco, A., España, E. y Franco-Mariscal, A. J. (2017). Estrategias didácticas para el desarrollo del pensamiento crítico en el aula de ciencias. Ápice, Revista de Educación Científica, 1(1), 107-115. DOI: https://doi.org/10.17979/arec.2017.1.1.2004

Blanco, A., España, E. y Rodríguez, F. (2012). Contexto y enseñanza de la competencia científica. Alambique: Didáctica de las ciencias experimentales, 70, 9-18.

Caamaño, A. (2015). Una reflexión conceptual y lingüística en torno a las diferentes denominaciones de las sustancias químicas. Alambique: Didáctica de las ciencias experimentales, 82, 9-16.

Campanario, J. M., Moya, A., y Otero, J.C. (2001). Invocaciones y usos inadecuados de la ciencia en la publicidad. Enseñanza de las Ciencias: 19(1), 45-56. Recuperado de: https://www.raco.cat/index.php/Ensenanza/article/viewFile/21709/21543

CEFIC-European Chemical Industry Council (2004). Pan European Survey, Image of the Chemical Industry 2004. Recuperado de: http://www.cefic.be/Files/Publications/ PES_04_Ex_Summ.doc

Chamizo, J. A. (2011). La imagen pública de la Química. Educación Química, 22(4), 320331. Recuperado de: http://www.scielo.org.mx/pdf/eq/v22n4/v22n4a7.pdf

Duffus, J. H., Nordberg, M. y Templeton, D. M. (2007). Glossary of terms used in toxicology, (IUPAC Recommendations 2007). Pure and Applied Chemistry, 79(7), 1153-1344. Recuperado de: http://citeseerx.ist.psu.edu/viewdoc/ download?doi=10.1.1.624.2331\&rep=rep1\&type=pdf

Ennis, R.H. (1996). Critical thinking. New York: Prentice Hall.

Ezquerra, A., Fernández Sánchez, B. y Magaña, M (2015). Verdad, mentira... verdad, mentira. Enséñame a decidir. Alambique: Didáctica de las ciencias experimentales, 81, 9-16.

FECYT (2018). Percepción social de la ciencia y la tecnología en España - 2018. Madrid: FECYT.

García-Carmona, A., Acevedo-Díaz, J. A. y Aragón-Méndez, M. A (2018). Comprensión del alumnado de Secundaria sobre la dimensión sociológica de la naturaleza de la ciencia a partir de la historia de la ciencia. Ápice. Revista de Educación Científica, 2(2), 43-54. DOI: https://doi.org/10.17979/arec.2018.2.2.4519

Girón, J. R., Blanco, A., y Lupión, T. (2015). Uso de la publicidad de un producto alimenticio para aprender un modelo sobre las defensas en el intestino humano. Un estudio en 30 de ESO. Revista Eureka sobre Enseñanza y Divulgación de las Ciencias, 12(2), 278-293. DOI: http://dx.doi.org/10.25267/Rev_Eureka_ensen_divulg_cienc.2015. v12.i2.04

Gisbert, F. J. G. y Pallejà, R. P. (2006). Esperanza de vida en España a lo largo del siglo XX: las tablas de mortalidad del Instituto Nacional de Estadística. Documentos de trabajo (Fundación BBVA), 11. Recuperado de: https://www.fbbva.es/wp-content/ uploads/2017/05/dat/DT_2006_11.pdf

Halpern, D. F. (1998). Teaching critical thinking for transfer across domains: Disposition, skills, structure training, and metacognitive monitoring. American psychologist, 53(4), 449-455. 
Jensen, W. B. (1998), Logic, history, and the teaching of chemistry: III. One chemical revolution or three? Journal of Chemical Education, 75 (8), 961-969.

Jiménez-Aleixandre, M. P. (2010). 10 ideas clave. Competencias en argumentación y uso de pruebas. Barcelona: Graó.

Jiménez-Liso, M.R., de Manuel, E., González, F. y Salinas, F. (2000). La utilización del concepto de $\mathrm{pH}$ en la publicidad y su relación con las ideas que manejan los alumnos: aplicaciones en el aula. Enseñanza de las ciencias, 18(3), 451-461.

Kuhn, D. (1992). Thinking as argument. Harvard Educational Review, 62(2), 155-178.

Lawrence J. F, White C. y Snow C. E. (2010). The words students need. Educational Leadership 68(2), 22-26.

Lawrence, J. F., White, C. y Snow, C. E. (2011). Improving Reading across Subject Areas with Word Generation. CREATE Brief. Center for Research on the Educational Achievement and Teaching of English Language Learners. Recuperado de: https:// files.eric.ed.gov/fulltext/ED549153.pdf

López-Nicolás, J. M. (2014). Ciencia y marketing: un matrimonio mal avenido. Nova Acta Científica Compostelana, 21, 19-25. http://www.usc.es/revistas/index.php/nacc/ article/view/2209/2220

López-Nicolás, J. M. (2016). Vamos a comprar mentiras. Palencia: Ed. Cálamo.

Martín del Pozo, R. y Galán Martín, P. (2012). Los criterios de clasificación de la materia inerte en la Educación Primaria: concepciones de los alumnos y niveles de competencia. Revista Eureka sobre enseñanza y divulgación de las ciencias, 9(2), 213-230. Recuperado de: https://revistas.uca.es/index.php/eureka/article/view/2768

Mulet, J.M. (2014). Comer sin miedo. Barcelona: Ediciones Destino.

OECD (2017), Health at a Glance 2017: OECD Indicators, OECD Publishing, Paris, DOI: https://doi.org/10.1787/health_glance-2017-en

Paul, R. y Elder, L. (2006). The miniature guide to critical thinking concepts and tools. Foundation for critical thinking. Recuperado de: http://www.criticalthinking.org/ files/Concepts_Tools.pdf

Pinker, S. (2018). En defensa de la llustración. Por la razón, la ciencia, el humanismo y el progreso. Barcelona: Paidós.

Pro, A. y Rodríguez, J. (2010). Aprender competencias en una propuesta para la enseñanza de los circuitos eléctricos en la educación primaria. Enseñanza de las Ciencias, 28(3), 385-404.

Real Decreto 1105/2014, de 26 de diciembre, por el que se establece el currículo básico de la Educación Secundaria Obligatoria y del Bachillerato. Recuperado de https:// www.boe.es/boe/dias/2015/01/03/pdfs/BOE-A-2015-37.pdf

Smolin, L. (2007). Las dudas de la física en el siglo XXI. Barcelona: Crítica.

Solbes, J. (2012). Contribución de las cuestiones sociocientíficas al desarrollo del pensamiento crítico (I): Introducción. Revista eureka sobre enseñanza y divulgación de las ciencias, 10(1), 1-10. Recuperado de: http://ojs.uca.es/index.php/tavira/ article/viewFile/329/pdf_118

Solbes, J., y Torres, N. (2013). Concepciones y dificultades del profesorado sobre el pensamiento crítico en la enseñanza de las ciencias. Enseñanza de las ciencias, (Extra), 
3389-3393. Recuperado de: https://ddd.uab.cat/pub/edlc/edlc_a2013nExtra/ edlc_a2013nExtrap3389.pdf

Valls, J. y Segura, M. (2015). La frontera entre las substancias naturales, artificiales y sintéticas: tres actividades experimentales. Alambique: Didáctica de las ciencias experimentales, 82, 39-44.

Vázquez-Alonso, A., y Manassero-Mas, M. A. (2006). El interés de los estudiantes hacia la química. Educación química, 17(3), 388-401.

Vieira, M.R., Tenreiro-Vieira, C. y Martins, I. (2010). Pensamiento crítico y literacia científica. Alambique: Didáctica de las ciencias experimentales, 65, 96-104.

Yager, R. E. (1993). Science and critical thinking. En J. H. Clarke y A. W. Biddle (Eds.), Teaching critical thinking: Reports from across the curriculum. Englewood Cliffs, NJ: Prentice Hall. 